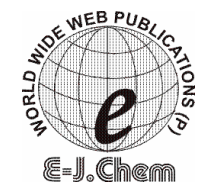

http://www.e-journals.net
ISSN: 0973-4945; CODEN ECJHAO

E-Journal of Chemistry

Vol. 5, No. 1, pp. 185-186, January 2008

\title{
QSAR Studies of 6-Amino Uracil Base Analogues : A Thymidine Phosphorylase Inhibitor in Cancer Therapy
}

\author{
SURYA PRAKASH B.N GUPTA*, NEERAJ UPMANYU* \\ N. S. HARI NARAYANA MOORTHY ${ }^{\S}$ and S. BHATTACHARYA ${ }^{\mathbb{I}}$, \\ *Rajiv Gandhi Institute of Pharmacy, Satna (M.P.)-485001. \\ \#RKDF, College of Pharmacy, Bhopal (M.P.)-462021.
}

§School of Pharmaceutical Sciences, UTD, RGPV, Gandhi Nagar, Bhopal (M.P.) 462036.

${ }^{\mathbb{I}}$ Department of Pharmaceutical Sciences, BIT Mesra, Ranchi (Jharkhand).

suryatony@yahoo.co.in

Received 24 November 2006; Revised 10 January 2007; Accepted 20 February 2007

\begin{abstract}
A novel series of 6-amino uracil base analogue were synthesized. QSAR study was used to relate the selective nonsubstrate inhibitory activity of 6-amino uracil base analogue with various physicochemical descriptors. Stepwise multiple regression analysis was performed to find out the correlation between various physicochemical descriptors and biological activity of the compounds by using Openstat 2 version 6.5.1 and valstat statistical software. Out of the several equations developed, the best equation having the highest significance was selected for further study. The equation is able to explain $60 \%$ of total variance and are more than $95 \%$ significant as revealed by the $\mathrm{F}$ value.
\end{abstract}

Keywords: 2D QSAR, 6-Amino Uracil base analogue, Anticancer, Valstat statistical software.

\section{Introduction}

Solid tumors are angiogenesis-dependent ${ }^{1}$. In the development of an anticancer therapy based upon the regression or inhibition of vascularization of the tumor mass it was recently found that thymidine phosphorylase (TP), an enzyme involved in thymidine metabolism and homeostasis, could play an important role in angiogenesis ${ }^{2,3}$. In our search for potent and selective nonsubstrate inhibitors of thymidine phosphorylase (TP), a novel series of 6-amino uracil base analogues were synthesized as per the reported paper ${ }^{4}$. The present study was undertaken to determine the physicochemical properties, which govern the anticancer activity with a view to provide a better rational design of some more potent drugs in the 
present series. The aim of this study was to select the highest significant physicochemical descriptors, which was correlated with biological activity.

\section{Experimental}

The biological activity data of various compounds for QSAR studies was obtained from Federico Focher $e a^{4}$. The biological activity was converted to -log (biological activity) to decrease the variance and to convert the data into free energy changes related value. The various physicochemical descriptors of the compounds obtained "substituent constant for correlation analysis in chemistry and biology developed by Corwin Hansch and Albert Leo". Indicator variables of the parent structure, the physicochemical descriptors and the data was fed into the excel worksheet and saved in comma delimited file. The correlation and inter correlation matrix between biological activities and various physicochemical descriptors and indicator variables were obtained using Openstat 2 version 6.5.1 and valstat statistical software. Multiple regression analysis was performed, which correlates biological activity with physicochemical descriptors. The best equations were selected with the consideration of statistical parameters ${ }^{5}$ such as correlation coefficient (r), squared correlation coefficient $\left(\mathrm{r}^{2}\right), \mathrm{F}_{\text {test }}$ value $\left(\mathrm{F}_{\text {test }}\right)$.

\section{Results and Discussion}

The minimum inter correlated descriptors were undergone stepwise multiple regression analysis. Among the equations obtained from the stepwise multiple regression analysis, the significant equations with high correlation are listed below.

$$
\begin{aligned}
& -\log \mathrm{IC}_{50}=0.824 \mathrm{R}_{2}(0.129)+1.444 \mathrm{R}_{3}(0.212)+0.761 \mathrm{HD}(0.105)-0.723 \\
& \mathrm{n}=19 ; \mathrm{r}=0.768 ; \mathrm{r}^{2}=0.590 ; \mathrm{F}=7.209
\end{aligned}
$$

The best equation for these inhibitors of angiogenesis in tumor cells revealed that the substituents at $R_{2}, R_{3}$ and $R_{4}$ contributed positively to the biological activity. The equation is able to explain $60 \%$ of total variance and is more than $95 \%$ significant as revealed by the $\mathrm{F}$ value.

\section{Conclusions}

The various results obtained after QSAR study could be helpful in designing new series of 6-amino uracil base analogues derivatives as novel anticancer molecule. The study can be extended with advanced techniques like CoMFA, CoMSIA, Docking etc which may further lead to design of novel anticancer molecules having better therapeutic index with low toxicity, higher oral bioavailability and solubility.

\section{References}

1. Folkman J, J. Natl. Cancer Inst. 1990, 82, 4.

2. Moghaddam A, Zhang HT, Fan T P, D E, Lees V C, Turley H, Fox S B, Gatter K C, Harris A L and Bicknell R, Proc. Natl. Acad.Sci. U.S.A. 1995, 92, 998.

3. Miyadera K, Sumizawa T, Haraguchi M, Yoshida H, Konstanty W, Yamada Y and Akiyama S, Cancer Res. 1995, 55, 1687.

4. Federico Ficher Daniela Ubiali, Massimo Pregnolato, Chengxin Zhi, Joseph Gambino, George E. Wright, and Silvio Spadari, J. Med. Chem. 2000, 43, 2601.

5. Hansch C, Sammes P G and Taylor J B, in: Comprehensive Medicinal Chemistry, $4^{\text {th }}$ Ed., Pergamon Press, Great Britain, 1990, 497. 


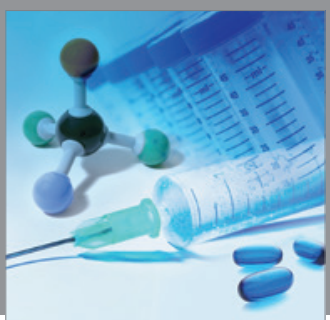

International Journal of

Medicinal Chemistry

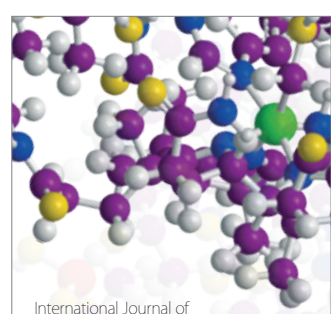

Carbohydrate Chemistry

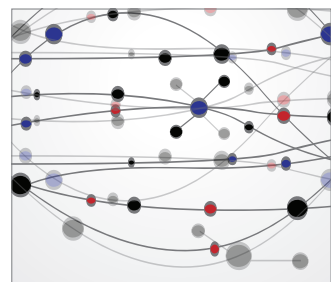

The Scientific World Journal
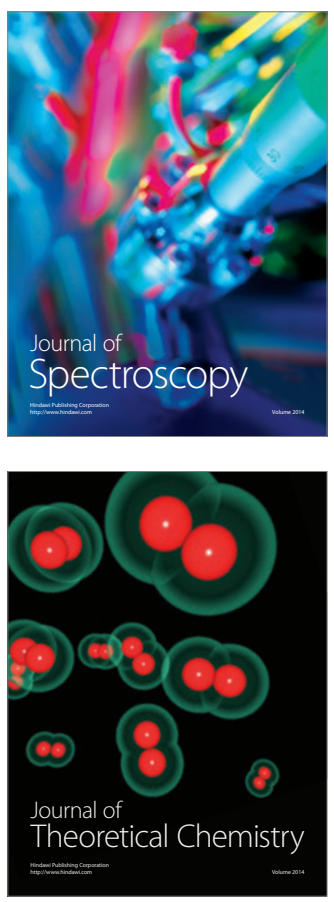
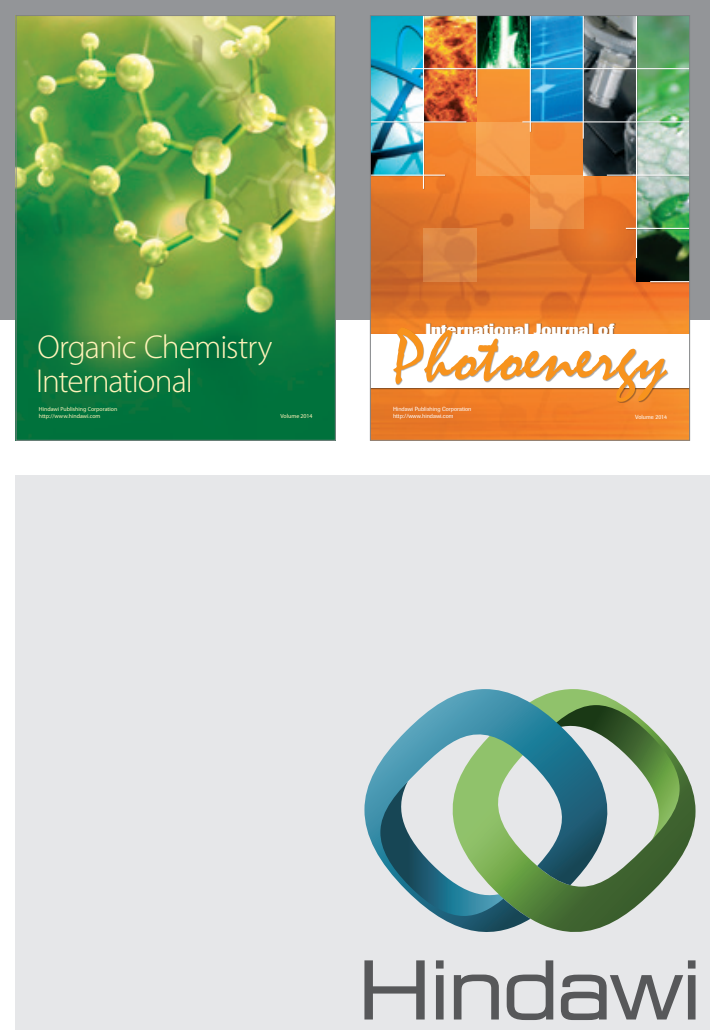

Submit your manuscripts at

http://www.hindawi.com
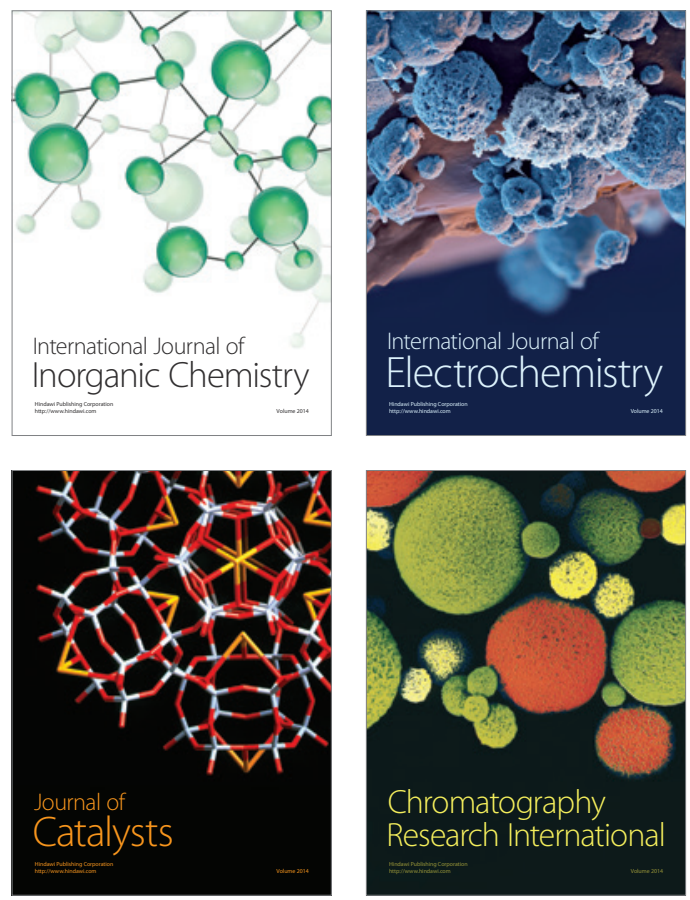
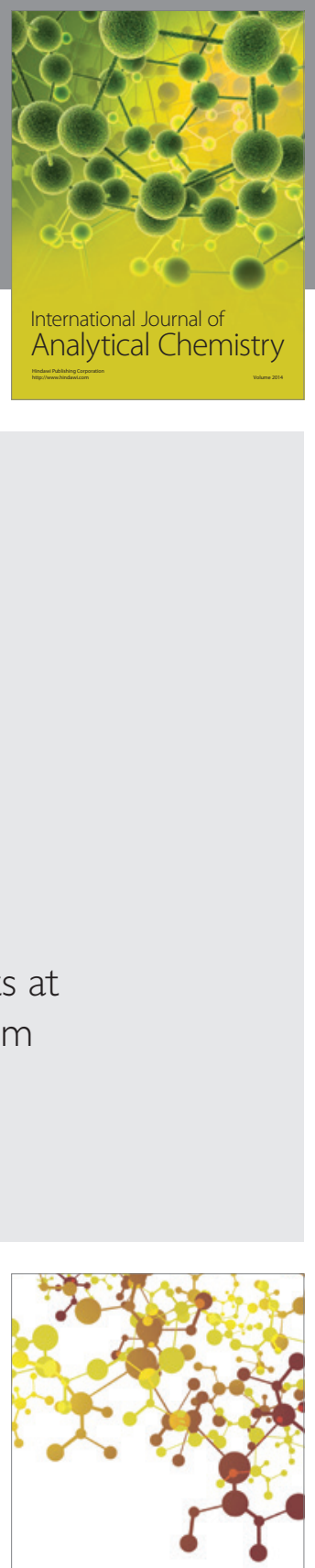

Journal of

Applied Chemistry
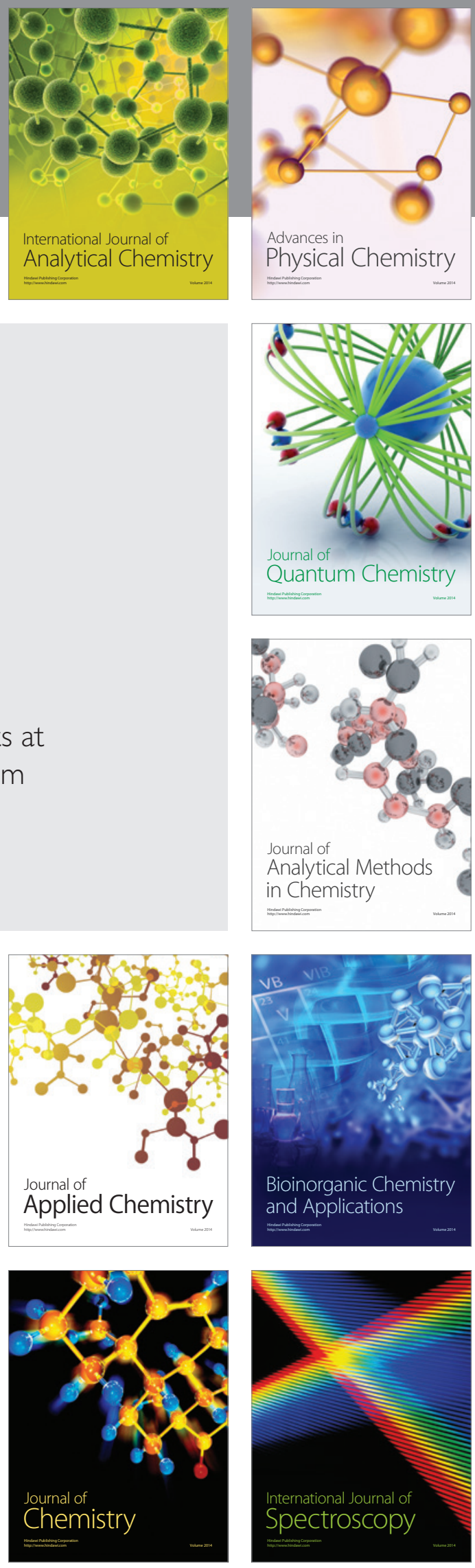